\title{
The Development of Pro-apoptotic Cancer Therapeutics
}

Noha I. Ziedan, Hachemi Kadri and Andrew D. Westwell"

Welsh School of Pharmacy, Cardiff University, Redwood Building, King Edward VII

Avenue, Cardiff, CF10 3NB, Wales, U.K.

\footnotetext{
* Address correspondence to this author at the Welsh School of Pharmacy, Cardiff University, Redwood Building, King Edward VII Avenue, Cardiff, CF10 3XF, UK; Tel: 44-2920-875800; E-mail: WestwellA@,cf.ac.uk
} 
Abstract: Resistance to apoptosis is one of the fundamental hallmarks of cancer. Recently, the selective induction of apoptosis in cancer cells has emerged as an exciting possibility for the development of future selective cancer therapy. This review will summarise the development of the major classes of small molecule "proapoptotic" antitumour agents.

Keywords: Pro-apoptotic cancer therapy, selective antitumour agents, apoptosis, small molecules, mitochondria-targeting, X-linked inhibitor of apoptosis (XIAP), Bcell lymphoma 2 (Bcl-2), aerobic glycolysis. 


\section{INTRODUCTION}

\subsection{Apoptosis and Cancer Therapy}

Apoptosis (programmed cell death) is a well-ordered and tightly-regulated physiological process that plays a pivotal role in development, cancer, and normal ageing [1]. Defects in apoptotic pathways contribute fundamentally to a range of disease states, whether involving too much apoptosis (e.g. Alzheimer's disease, multiple sclerosis) or too little (e.g. cancer, rheumatoid arthritis). Many reviews on the role and importance of apoptosis in cancer have been published and resistance to apoptosis is well known as one of the six hallmarks of cancer articulated by Hanahan and Weinberg [2].

Apoptosis is induced via two main routes known as the intrinsic pathway (channelling through the mitochondria) and the extrinsic pathway (involving activation of death receptors) [3]. Mitochondria are well-established as central players in the cell death process, and mitochondrial membrane permeabilisation, leading to the subsequent release of apoptogenic factors (such as cytochrome c etc.) and caspase activation, usually has grave consequences for the cell [4].

The discovery of small molecule drugs capable of inducing apoptosis directly and selectively in cancer cells (pro-apoptotic cancer therapy) is a fundamental and highly attractive goal of cancer drug discovery. Pro-apoptotic agents would be expected to have the following beneficial effects compared to existing molecularly targeted and cytotoxic cancer therapeutics:

- Tumour cells would be eliminated and would be unable to contribute to tumour relapse (as may the case for cytostatic agents), and drug resistance. 
- Apoptosis is a particularly efficient mode of cell death (preferable to necrosis for example), and does not produce inflammation and damage to the surrounding tissue.

- Agents that induce apoptosis directly would not be mutagenic, and would be less prone to development of drug resistance. Indeed the depolarisation of the mitochondrial membrane and release of pro-apoptotic factors such as cytochrome c most often represents the point-of-no-return for a cancer cell destined to die through apoptosis.

- Severe toxicological side effects traditionally associated with cytotoxic (genotoxic) cancer chemotherapy should be avoided by selective pro-apoptotic activity on cancer cells lines at the expense of normal tissue.

\subsection{Scope of the Review}

Since most cancer chemotherapeutic agents (irrespective of their primary mechanism of action) ultimately lead to apoptotic cell death, the role of apoptosis in mediating the cell death process might be considered ubiquitous. It is not our intention to provide a global survey of antitumour agents that induce apoptosis. We will here focus on agents that are known to induce apoptosis directly, independent of p53 and other indirect factors such as cell cycle status. These direct pro-apoptotic effects are most often based on agents able to target mitochondria and their associated protein complexes. We will broadly focus on pro-apoptotic agents where there is reported selectivity between cancer and normal cells, i.e. supporting data regarding relative inactivity in normal cells.

One related group of pro-apoptotic compounds that will not be described in detail here are the naturally occurring dietary agents that might best be described as 
cancer chemopreventative agents. Such agents in general have a complex pharmacology and pharmacokinetics, and rather weak pro-apoptotic activity, but are of interest here due to their minimal toxicity as dietary components. The green tea polyphenol epigallocatechin-3-gallate [5], the red grape/wine constituent resveratrol [6], and the chilli pepper constituent and vanilloid ligand capsaicin [7] provide examples of this class of agent.

The review will concentrate exclusively on small molecules, and the development of "biological agents" such as agonistic antibodies targeting TRAIL death receptors (extrinsic apoptosis pathway) [8] will not be discussed here.

\section{PRO-APOPTOTIC ANTITUMOUR AGENTS IN DEVELOPMENT}

In a number of cases, the primary molecular target for selective pro-apoptotic molecules is unknown. We will classify recently reported selective pro-apoptotic agents in development for the treatment of cancer on the basis of molecular target, where this is known. This survey of pro-apoptotic agents provides a snapshot of what we consider to be the most important pro-apoptotic agents in development, and is by no means comprehensive. Our criteria for selection of compounds for inclusion here is based on:

- Cellular potency of pro-apoptotic activity (in vitro / in vivo).

- Lack of activity in cellular models of normal tissue and/or lack of in vivo toxicity.

It is interesting to note that there are widely used anticancer agents in the clinic that have been studied with respect to their direct effects on isolated mitochondria and apoptosis induction. Since this review is limited to selective pro-apoptotic agents in development for cancer, studies in this area will not be considered in detail here (this 
area has been reviewed, for example, by Debatin and co-workers [9]). For example, established cancer chemotherapeutic agents such as paclitaxel [10] (through interaction with the voltage-dependent anion channel) and etoposide [11] have previously been shown to induce mitochondrial membrane permeabilisation (MMP) and apoptosis in isolated mitochondria.

\subsection{Direct mitochondria-targeted agents}

The field of mitochondrial biochemistry has recently been undergoing something of a renaissance, in part due to the enticing possibility that mitochondria might represent a target for selective pro-apoptotic cancer therapy [12]. An early example of selective induction of apoptosis in vitro (albeit in a limited range of cancer cell lines) came from the synthesis and evaluation of a library ( 88 members) of amides based on a pro-apoptotic natural product from Isodon excisus [13]. The most potent compound of the series against the U-937 lymphoma cell line $\left(\mathrm{IC}_{50} 44 \mu \mathrm{M}\right)$ was found to be $\mathbf{1}$ (Figure 1), and cells treated with this agent showed several hallmarks of apoptotic cell death (e.g. caspase-3 induction and activity, and mitochondrial depolarization). Importantly compound $\mathbf{1}$ showed virtually no toxicity toward actively dividing mouse splenocytes $\left(\mathrm{IC}_{50}>1000 \mu \mathrm{M}\right)$, suggestive of selective cytotoxicity via apoptosis induction.

\section{Arsenic-based compounds}

Thiol-interactive arsenic-based compounds, such as phenylarsenoxide (PAO), have been found to induce MMP in isolated mitochondria [14] through a mechanism involving interaction with two unpaired cysteine residues in the adenine nucleotide 
translocator (ANT), an important mitochondrial permeability transition pore protein that spans the inner mitochondrial membrane [15].

A tripeptide derivative of $\mathrm{PAO}, \quad 4-(\mathrm{N}-(\mathrm{S}-$ glutathionylacetyl)amino)phenylarsenoxide (GSAO, 2, Figure 1) has been synthesised and also found to inactivate the ANT through cross-linking residues $\mathrm{Cys}^{160}$ and $\mathrm{Cys}^{257}$ in a stable ring structure [16]. GSAO caused a concentration-dependent increase in superoxide levels, ATP depletion, mitochondrial depolarization, and apoptosis selectively in proliferating, but not growth quiescent, endothelial cells. In addition, GSAO was selectively toxic towards endothelial cells, and inhibited angiogenesis in the chick chorioallantoic membrane and in solid tumours in mice, with no apparent toxicity at efficacious in vivo growth inhibitory doses.

\section{Jasmonates}

The jasmonates (3, Figure 1) are a group of plant stress hormones that have been found to inhibit proliferation and induce cell death in vitro in a range of human cancer cell lines (breast, prostate, melanoma, lymphoma, and leukemia) in a manner independent of cellular transcription, translation and p53 expression [17,18]. More recent studies on the mechanism of antitumour activity of jasmonates point decisively to the direct and selective action on human cancer cell mitochondria [19].

Jasmonates were found to induce membrane depolarization and cytochrome c release in intact Molt-4 cells. Importantly jasmonates induced swelling in mitochondria isolated from Hep3B hepatoma cells, but not in mitochondria isolated from 3T3 nontransformed (immortalised) cells or from normal lymphocytes, through interactions at the mitochondrial permeability transition pore complex (PTPC). In addition, jasmonates induce mitochondrial perturbation in chronic lymphocytic 
leukaemia (CLL) cells taken from patients. Since proliferating normal cells were found to be insensitive to the effects of jasmonates, a mechanism exploiting mitochondrial characteristics that are differentially expressed in cancer cells is implied.

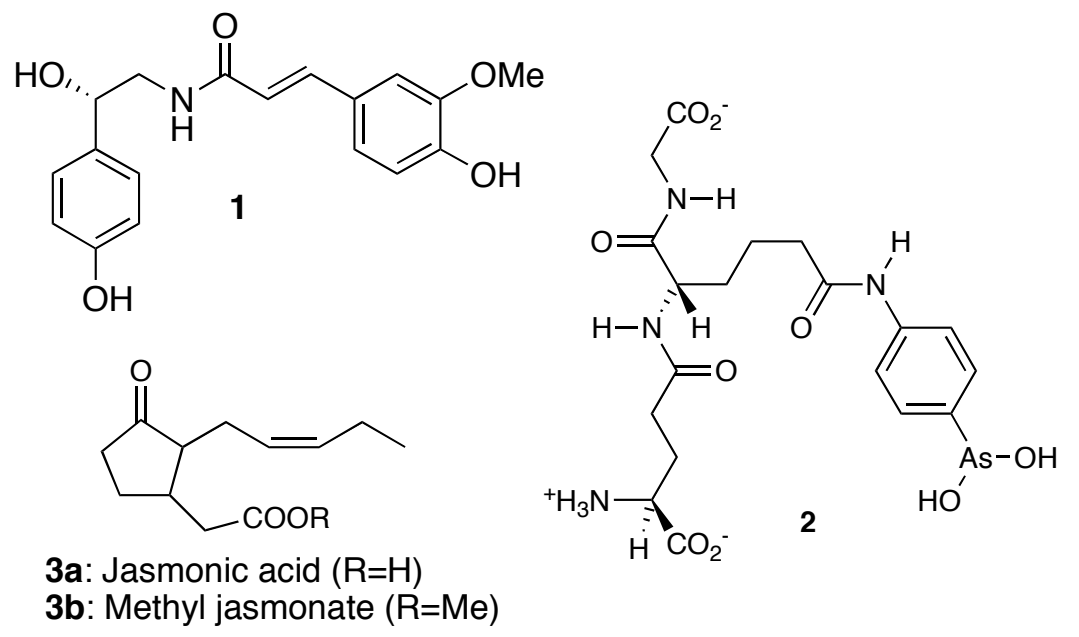

Fig. (1). Examples of mitochondria-targeted pro-apoptotic agents.

\subsection{Targeting tumour bioenergetic pathways}

\section{Dichloroacetate (DCA)}

It is well established that cancer cells exhibit a unique metabolic profile whereby aerobic glycolysis is the main source of energy compared to oxidative phosphorylation in normal cells, a phenomenon known as the "Warburg effect" [20]. In a recent intriguing study, Bonnet et al. demonstrated that a simple commercially available chemical, the sodium salt of dichloroacetate (DCA) selectively induces apoptosis, reduces proliferation and inhibits growth of cancer cells by reversing this metabolic re-modelling process [21].

DCA-mediated antitumour effects were found to mainly involve the inhibition of mitochondrial pyruvate dehydrogenase kinase (PDK2), causing depolarisation of 
the mitochondrial membrane and allowing efflux of pro-apoptotic factors and apoptosis induction [21]. In addition, it was also demonstrated that DCA causes the up-regulation and activation of Kv1.5 potassium channels through the inhibition of NFAT1 (nuclear factor of activated T lymphocytes) leading to a decreased cellular $\left[\mathrm{K}^{+}\right]_{\mathrm{I}}$ and hence activating caspases. In vivo studies have shown that using clinically relevant DCA doses in the drinking water of rat models effectively led to the inhibition and prevention of tumour growth with no observed toxicity [21]. Indeed, these findings raise hopes of having an orally potent and cost-effective antitumour agent. However, growing evidence suggests that the plasticity of tumour cells enables them to activate other non-glycolytic pathways to secure their energy, posing issues of drug resistance [22].

\subsection{XIAP Targeted agents:}

Inhibitors of apoptosis proteins (IAPs) are endogenous caspase inhibitors that bind and inhibit caspases $-3,-7$ and -9 . Eight members of the IAP family are known so far [23], of which X-linked inhibitor of apoptosis protein (XIAP) is the best characterized in term of its inhibitory mechanism. XIAP has three BIR domains (BIR 1-3) and a RING finger that binds and inhibits caspases [24]. The BIR-3 domain of XIAP inhibits caspase-9, while BIR-1 and -2 are more specific for caspases -3 and -7 $[25-27]$.

Smac-DIABLO is a protein released from the mitochondria in response to apoptotic stimuli and directly interacts with XIAP, functioning as an endogenous inhibitor of the IAP family [26,27]. Targeting the IAP family came from the finding that the levels of different IAP family members were elevated in several tumours, thus providing a possible mechanism for inducing apoptosis directly and specifically to 
treat cancer [28-30]. Since small molecule inhibitors of XIAP have been recently reviewed [31-33], we will focus here on two examples of XIAP inhibitors selected from the literature on the basis of their pro-apoptotic properties.

\section{Embelin}

Embelin (4) was discovered through computational structure-based screening of an in-house traditional herbal medicine three-dimensional structure database of 8221 individual natural products [34]. Embelin, extracted from the Japanese Ardisia herb, was found to bind to the XIAP BIR-3 domain. It selectively inhibited cell growth and induced apoptosis in prostate cancers known to over-express XIAP with minimal effect on normal cells. Embelin inhibited cell growth of both PC-3 and LNCap cells with an $\mathrm{IC}_{50}$ of $3.7 \mu \mathrm{M}$ and $5.7 \mu \mathrm{M}$ respectively, whilst in a caspase activation assay, embelin was found to effectively activate caspase-9 and to induce early apoptosis. More recent studies on embelin derivatives have identified new and potent XIAP BIR3 inhibitors with pro-apoptotic properties in human cancer cells [35].

\section{Smac mimetics}

Most of the designed Smac mimetics depend on replacing the valine in the Smac based AVPI peptide with an unnatural amino acid. These Smac mimetic XIAP inhibitors act by binding more strongly to BIR-3, inhibiting the binding of caspase- 9 to XIAP at this site thus antagonizing its inhibitory effect and inducing apoptosis.

A series of tripeptides was described by Oost et al. [36] that bind to XIAP BIR-3 domain with nanomolar affinities. The most active compound of the series (5) showed a wide range of potencies against a diverse panel of human cancer cell lines ranging from a single-digit nanomolar activity in certain types to no activity at up to 
$50 \mu \mathrm{M}$ concentration in other cell types. The most potent in vitro activity was observed against the human breast cancer cell lines BT-549 and MDA-MB-231, the melanoma cell line SK-MEL-5, and the acute promyelocytic leukaemia HL-60. Interestingly, there was no correlation between the potency of (5) and the expression of XIAP. Measuring caspase-3 activation in MDA-MB-231 cells treated with (5) showed an up to 8-fold increase in caspase-3 activity in a dose-dependent manner. Apoptosis was induced by (5) in absence of an identified apoptotic stimuli. In in vivo testing (MDA-MB-231 flank breast cancer xenograft model), a $20 \mathrm{mg} / \mathrm{kg} /$ day dose of (5) inhibited tumour growth rates by $50-60 \%$.<smiles>CCCCCCCCCCCC1=C(O)C(=O)C=C(O)C1=O</smiles><smiles>CNC(C)C(=O)NC(C(=O)N1CCC[C@H]1C(=O)N[C@H]1CCCc2ccccc21)C1CCCCC1</smiles>

Fig. (2). Examples of XIAP-targeted pro-apoptotic agents.

\subsection{Bcl-2 targeted agents}

The B-cell lymphoma 2 (Bcl-2) family of proteins is composed of more than 20 members [37-39]. Some members such as Bcl-2, Bcl ${ }_{\mathrm{XL}}, \mathrm{Bcl}-\mathrm{W}$ and $\mathrm{Mcl}-1$ are antiapoptotic, whilst others are pro-apoptotic such as Bax, Bak, Bid and Bim. Both family members cooperate through protein-protein interactions to mediate the intrinsic apoptotic pathway $[40,41]$.

Anti-apoptotic Bcl-2 family members protect cells from apoptosis by inhibiting the action of pro-apoptotic members $[42,43]$. Three-dimensional studies of 
anti-apoptotic Bcl-2 proteins revealed the presence of a hydrophobic groove that acts as a binding site for the $\mathrm{BH} 3$ peptide domain of pro-apoptotic Bcl-2 members [44]. Agents that are designed to target these binding grooves are predicted to induce apoptosis in cancer cells (which over-express these anti-apoptotic proteins) by antagonizing their protective effect.

Over the past 10 years, several non-peptidic small molecule inhibitors to antiapoptotic Bcl-2 proteins have been introduced and some of them are already in clinical trials as single-agent chemotherapy, such as the Phase 1 orally bioavailable pan-Bcl-2 inhibitor AT-101 from Ascenta Therapeutics [45]. Since the development of Bcl-2 modulatory small molecules as potential anticancer therapeutics has been reviewed in recent years (for examples, see $[8,46]$ ), discussion here will be limited to the most relevant potent and selective pro-apoptotic agents only.

\section{HA 14-1}

Ethyl-2-amino-6-bromo-4-(1-cyano-2-ethoxy-2-oxoethyl)-4H-chromene-3carboxylate (HA 14-1, 6a) was one of the first identified small molecule inhibitors of anti-apoptotic Bcl-2 proteins [47]. HA 14-1 competes with the Bak BH3 domain for binding to the Bcl-2 hydrophobic groove with a $\mathrm{K}_{\mathrm{i}}$ value of $9 \mu \mathrm{M}$. It was found to induce apoptosis in human acute myeloid leukaemia (HL-60) cells and H1299 cells at a concentration of 20-50 $\mu \mathrm{M}$ [47] and was found to induce apoptosis selectively in cell lines that over-express anti-apoptotic Bcl-2 proteins [48-49].

Studies made to ascertain the mechanism of apoptotic action revealed that HA 14-1 causes a release of $\mathrm{Ca}^{2+}$ from the endoplasmic reticulum and decreases the mitochondrial membrane potential resulting in a release of cytochrome c into the cytosol [47], which in turn forms a complex with Apaf-1 causing activation of 
caspase-9 [50]. Several studies have shown that HA 14-1 potentiates the action of many anti-cancer agents by antagonizing the Bcl-2 which protect cells from apoptosis [51-52] suggesting its use in combined therapy. Modification of the structure of HA 14-1 led to compound (6b) with a $\mathrm{GI}_{50}$ of $0.99 \mu \mathrm{M}$ for Jurkat cells (compared to a $\mathrm{GI}_{50}$ of $20 \mu \mathrm{M}$ for HA 14-1) [53].

\section{Gossypol}

(-)- Gossypol (7), a natural polyphenolic compound isolated from cotton seed, was identified as a small molecule inhibitor of $\mathrm{Bcl}-2$ and $\mathrm{Bcl}_{\mathrm{XL}}$ proteins [54]. (-)Gossypol binds to the $\mathrm{BH} 3$ binding groove of $\mathrm{Bcl}-2$, $\mathrm{Bcl}_{\mathrm{XL}}$ and $\mathrm{Mcl}-1$ with $\mathrm{K}_{\mathrm{i}}$ values of 320, 480 and $180 \mathrm{nM}$ respectively, and induces apoptosis in Jurkat cells overexpressing Bcl-2 and $\mathrm{Bcl}_{\mathrm{XL}}$ with $\mathrm{IC}_{50}$ values of 18.1 and $22.9 \mu \mathrm{M}$ respectively [54]. Induction of apoptosis with (-)-gossypol is associated with cytochrome c release and caspase-3 activation [54]. Gossypol has shown to possess antitumour activity against several tumor types [55-59] and it is now in clinical trials as a novel orally bioavailable anticancer agent.

\section{$T W-37$}

TW-37 (8) is another polyphenolic compound discovered through structurebased design that binds to the $\mathrm{BH} 3$ binding groove of Bcl-2 [60]. TW-37 was found to bind to $\mathrm{Bcl}-2, \mathrm{Bcl}_{\mathrm{XL}}$ and $\mathrm{Mcl}-1$ with $\mathrm{K}_{\mathrm{i}}$ values of 290, 1100 and $260 \mathrm{nM}$ respectively, while ELISA assay showed TW-37 to bind to Bcl-2 with an $\mathrm{IC}_{50}$ value of $0.7 \mu \mathrm{M}$. In vitro growth inhibition assay showed that TW-37 inhibits cell growth of PC-3 cancer cells with an $\mathrm{IC}_{50}$ of $200 \mathrm{nM}$. The TUNEL assay, on the other hand, showed that TW37 can potently induce apoptosis, where $90 \%$ of PC-3 cancer cells treated with TW-37 
(5 $\mu \mathrm{M}$ ) underwent apoptosis [60]. In vitro, TW-37 showed significant antiproliferative effects in a chemoresistant WSU-DLCL2 lymphoma cell line and in primary cells obtained from a lymphoma patient with no effect on normal peripheral blood lymphocytes. Co-immunoprecipitation experiments showed that TW-37 disrupted heterodimer formation between Bax or truncated-Bid and antiapoptotic Bcl2 and caused apoptotic cell death [61]. Additional anti-angiogenic properties associated with TW-37 have also been reported (outside the scope of this review) [62].

\section{ABT 737}

ABT 737 (9) was discovered through high-throughput NMR-based screening of a chemical library to identify small molecules that bind to the $\mathrm{BH} 3$ binding groove of $\mathrm{Bcl}_{\mathrm{XL}}$ [64]. ABT-737 was found to bind to $\mathrm{Bcl}-2, \mathrm{Bcl}_{\mathrm{XL}}$ and $\mathrm{Bcl}-\mathrm{w}$ with high affinity $\left(\mathrm{K}_{\mathrm{i}} \leq 1 \mathrm{nM}\right)$. ABT-737 did not itself induce release of cytochrome $\mathrm{c}$, but inhibited Bcl-2 protection at concentrations $\leq 10 \mathrm{nM}$ by blocking the inhibition of Bid-mediated cytochrome $\mathrm{c}$ release through binding to the $\mathrm{BH} 3$ binding groove of $\mathrm{Bcl}-2$. This binding disrupted the protein-protein interaction between $\mathrm{Bcl}_{\mathrm{XL}}$ and proapoptotic Bcl-2 proteins.

ABT-737 was found to be active both as a single agent or when used in combination with other chemotherapies or radiation, where it reduced the $\mathrm{EC}_{50}$ of several antitumour agents by $2-4$ fold. As a single agent, it displayed potent cytotoxicity in several lymphomas and SCLC, where it had an $\mathrm{EC}_{50}$ of $0.13-0.85 \mu \mathrm{M}$ when used in $\mathrm{t}(14: 18)$ chromosomal translocation-containing lymphoma cell lines. As an inhibitor of anti-apoptotic Bcl-2 ABT-737 exhibited pro-apoptotic activity and induced apoptosis in a concentration-dependent matter in patient-derived chronic 
lymphocytic B-cell leukaemia (CLC). In vivo, ABT-737 caused complete regression of established SCLC tumour xenografts as a result of apoptotic cell death. ABT-737 induced apoptosis selectively in cancer cells without affecting normal cells, where a significant increase in caspase-3 was noticed in tumour cells but not in liver, heart or intestinal normal cell lines [63].

\section{YC 137}

YC 137 (10) was discovered through structure-based design of small molecule inhibitors of anti-apoptotic Bcl-2. YC 137 was found to inhibit the binding of BidBH3 peptide to the Bcl-2 hydrophobic groove [64]. Hematopoeitic progenitors and cancer cells over-expressing Bcl-2 were found to be more sensitive to YC 137, and induction of apoptosis by this compound was selective to cancer cells expressing high levels of Bcl-2 such as CD34+ progenitors, myoblasts and peripheral blood mononuclear cells, without affecting normal cells. In vitro selection of breast cancer cell lines resistant to YC 137 showed a reduced expression of Bcl-2 correlating with low activation of signal transducer and activator of transcription 3 (Stat3) in addition to reduced expression of the human growth factor receptor-2 (HGR2), and such cells were found to be more sensitive to apoptosis induced by chemotherapy [64].

\section{Flexible heteroarotinoids (Flex-Hets)}

Flexible heteroarotinoids, more commonly shortened to Flex-Hets, represent a novel class of potent antitumour compounds which selectively induce apoptosis in a wide range of cancer cell lines [65]. The lead compound in this class SHetA2 (11) induces high levels of apoptosis at low micromolar concentrations, with a broad spectrum of activity in the NCI human cancer cell line panel [66] as well as cervical 
and head \& neck cancer cell lines [67].

Flex-Hets were developed from the antitumour heteroarotinoids by introducing urea or thiourea linkers to confer more flexibility to their structures [65]. Whilst nuclear retinoic acid receptor activation accounts for most of the antitumour properties of heteroarotinoids, Flex-Hets were found to have a distinct mechanism of action which entails the activation of the intrinsic mitochondrial pathway as well as the generation of reactive oxygen species (ROS) [66], as a consequence of mitochondrial swelling [68]. In addition, it was also demonstrated that the observed differential effects of Flex-Hets on cancer cells versus normal cells are likely attributed to their targeting of Bcl-2 family proteins. Flex-Hets reduce the levels of anti-apoptotic $\mathrm{Bcl}_{\mathrm{XL}}$ and $\mathrm{Bcl}-2$ proteins in cancer cell lines in contrast to normal cell lines where the expression of these proteins increases; pro-apoptotic Bax proteins levels remained unaltered in both cell types [68]. SHetA2 exhibited potent and selective antitumour properties in preclinical in vivo studies [69], suggesting translation of this work into the clinical setting in the near future.

\section{Stapled peptides}

A highly promising approach towards targeting $\alpha$-helical protein-protein interactions, using peptides stabilised using a chemical strategy termed "hydrocarbon stapling", has been applied to generate helical, protease-resistant, and cell-permeable $\mathrm{BH} 3$ peptide derivatives that bind with high affinity to multidomain Bcl-2 family members. One of these "stabilized alpha-helix of Bcl-2 domain" (SAHB) peptides was found to effectively inhibit the growth of human leukaemia xenografts in vivo [70], and to trigger the functional activation of pro-apoptotic Bax at nanomolar doses in vitro [71]. 
Further development of these stable and specific stapled peptides is eagerly anticipated.<smiles>[R]c1ccc2c(c1)C(C(C#N)C(=O)OCC)C(C(=O)OCC)=C(N)O2</smiles>

6a $(\mathrm{R}=\mathrm{Br})$

6b (R=t-butylphenyl)

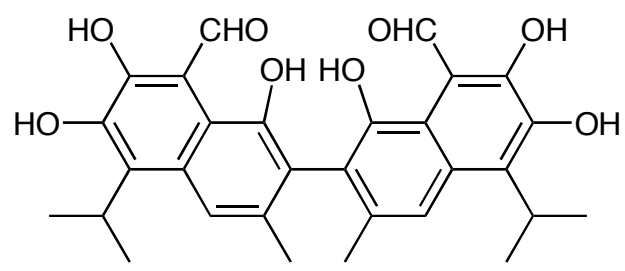<smiles>CC(C)c1ccccc1Cc1cc(C(=O)Nc2ccc(S(=O)(=O)c3ccccc3C(C)(C)C)cc2)c(O)c(O)c1O</smiles>

(-)-Gossypol (7)<smiles>CN(C)CC[C@H](CSc1ccccc1)Cc1ccc(S(=O)(=O)CC(=O)c2ccccc2)cc1[N+](=O)[O-]</smiles><smiles>COC(=O)N[C@@H](CCSC)C(=O)Oc1ccc(Nc2nc3c(s2)C(=O)c2ccccc2C3=O)cc1</smiles><smiles>CC1(C)CC(C)(C)c2cc(NC(=S)Nc3ccc([N+](=O)[O-])cc3)ccc2S1</smiles><smiles>CCc1ccccc1-c1ccc(Cl)cc1</smiles>

SHetA2 (11)

Fig. (3). Examples of Bcl-2 family-targeted pro-apoptotic agents.

\subsection{Pro-apoptotic agents with miscellaneous (defined) molecular targets}

\section{3-Aryl-5-aryl-1,2,4-oxadiazoles}

5-(3-Chlorothiophen-2-yl)-3-(4-trifluoromethylphenyl)-1,2,4-oxadiazole

was identified as a novel apoptosis inducer through a high-throughput caspase- and cell-based screening assay [72]. The apoptosis inducing activity of this compound was 
further characterized by a caspase-activation assay in SKBr3 cells, where a reduction of pro-caspases and appearance of active caspase-3 and -7 was identified. Compound 12 induced apoptosis selectively in certain cancer cell lines including the breast cancer cell lines T47D and ZR75-1 and colorectal cancer cell lines DLD-1 and HT29, with $\mathrm{EC}_{50}$ 's in the range 0.44 to $3.34 \mu \mathrm{M}$ [72].

A chemical genetics approach was applied to identify the molecular target of this compound, where several key genes including cyclin $\mathrm{D}_{1}$, transforming growth

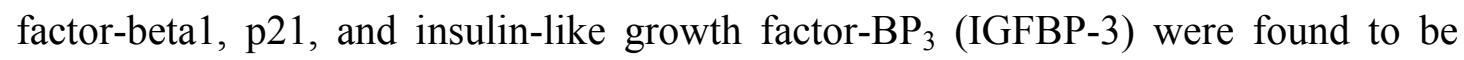
altered in cells that are sensitive to this compound. Applying a photoaffinity-labelling methodology, tail interacting protein 47 (TIP47), an insulin-like growth factor II (IGF II) receptor binding protein, was identified as the molecular target [73], where it was down-regulated in cells treated with this compound. TIP47 is known to bind to mannose-6-phosphate receptor (MPR) and it plays a role in the transport of this receptor from endosomes to the golgi network [74]. The over-expression of TIP47 in several tumour types has also been reported [75], suggesting that it may be a potentially useful anticancer target.

\section{Gambogic acid derivatives}

Gambogic acid (13), a natural product isolated from the resin of the Garcinia Hurburys tree, was first identified as a potent apoptosis inducer through a highthroughput screening assay [76]. The apoptosis inducing activity of this compound was characterized by a caspase activation assay in T47D cancer cells, where (13) had an $\mathrm{EC}_{50}$ of $0.78 \mu \mathrm{M}$ [76]. Further indication of the apoptosis inducing activity came from the observed nuclear fragmentation when cells were treated with (13) which could be protected by a pan-caspase inhibitor (EP1013) [77]. In flow cytometry 
assays in T47D cells, (13) was observed to induce apoptosis independent of cell cycle status [74]. Activation of caspase-8, cleavage of Bid and release of cytochrome $\mathrm{c}$ from the mitochondria were all observed after treating Jurkat cells with (13) [78].

The molecular target of gambogic acid derivatives was reported to be the transferrin receptor I (TfR) [78], a trans-membrane protein that plays a role in the transport of iron into cells through its interaction with transferrin. Binding assays showed that there is a good correlation between the affinity of gambogic acid derivatives to TfR and their ability to induce apoptosis. The binding site for (13) was found to be different from that of transferrin, suggesting a unique binding site and mechanism of action of these compounds [79]. Moreover, TfR was reported to be over-expressed in certain tumour types [79], suggestive that inhibitors of TfR could have useful anti-cancer activity.

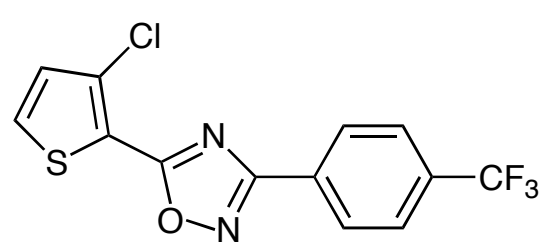

12

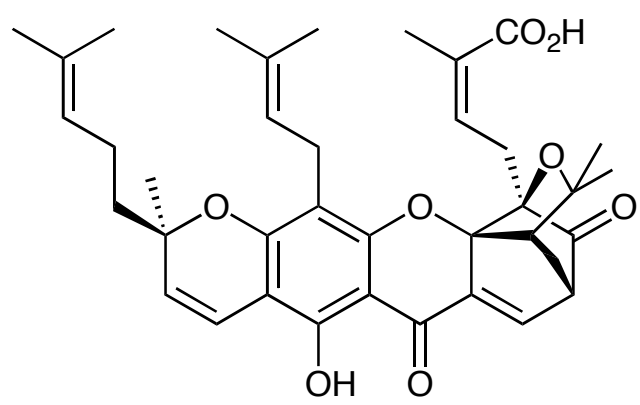

Gambogic acid (13)

Fig. (4). Examples of pro-apoptotic agents with miscellaneous (defined) targets.

\section{FUTURE PERSPECTIVES}

The direct and selective induction of apoptosis in human cancer cells through targeting components of the mitochondrial membrane (e.g. the Bcl-2 family) has been illustrated. Future challenges remain in translating promising pro-apoptotic molecules into the clinic, and further delineation of their pharmacological basis for antitumour 
activity. The prospect of mitochondrially-targeted agents exhibiting potent but selective activity against human cancer cells with a wide therapeutic window, remains an enticing prospect.

\section{ACKNOWLEDGEMENTS}

We gratefully acknowledge the support of the Egyptian Government (NZ) and Algerian Government (HK) for postgraduate studentships.

\section{REFERENCES}

[1] Thompson, C.B. Science. 1995, 5203, 1456.

[2] Hanahan, D.; Weinberg, R.A. Cell 2000, 100, 57.

[3] Okada, H.; Mak, T.W. Nat. Rev. Cancer 2004, 4, 592.

[4] Newmeyer, D.D.; Ferguson-Miller, S. Cell 2003, 112, 481.

[5] Noda, C.; He, J.; Takano, T.; Tanaka, C.; Kondo, T.; Tohyama, K.; Yamamura, H.; Tohyama, Y. Biochem. Biophys. Res. Comm. 2007, 362, 951.

[6] Fulda, S.; Debatin, K.M. Cancer Det. Prevent. 2006, 30, 217.

[7] Athanasiou, A.; Smith, P.A.; Vakilpour, S.; Kumaran, N.M.; Turner, A.E.; Bagiokou, D.; Layfield, R.; Ray, D.E.; Westwell, A.D.; Alexander, S.P.H.; Kendall, D.A.; Lobo, D.N.; Watson, S.A.; Lophatanon, A.; Muir, K.A.; Guo, D.; Bates, T.E. Biochem. Biophys. Res. Comm. 2007, 354, 50.

[8] Fesik, S.W. Nat. Rev. Cancer 2005, 5, 876.

[9] Debatin, K-M.; Poncet, D.; Kroemer, G. Oncogene 2002, 21, 8786.

[10] André, N.; Braguer, D.; Brasseur, G.; Gonçalves, A.; Lemesle-Meunier, D.; Guise, S.; Jordan, M.A.; Briand, C. Cancer Res. 2000, 60, 5349. 
[11] Robertson, J.D.; Gogvadze, V.; Zhivotovsky, B.; Orrenius, S. J. Biol. Chem. 2000, 275,32438 .

[12] Newmeyer, D.D.; Ferguson-Miller, S. Cell 2003, 112, 481.

[13] Nesterenko, V.; Putt, K.S.; Hergenrother, P.J. J. Amer. Chem. Soc. 2003, 125, 14672.

[14] McStay, G.P.; Clarke, S.J.; Halestrapp, A.P. Biochem. J. 2002, 367, 541.

[15] Halestrap, A.P.; Woodfield, K.Y.; Connern, C.P. J. Biol. Chem. 1997, 272, 3346.

[16] Don, A.S.; Kisker, O.; Dilda, P.; Donoghue, N.; Zhao, X.; Decollogne, S.; Creighton, B.; Flynn, E.; Folkman, J.; Hogg, P.J. Cancer Cell 2003, 3, 497.

[17] Fingrut, O.; Flescher, E. Leukemia 2002, 16, 608.

[18] Rotem, R.; Fingrut, O.; Moskovitz, J.; Flescher, E. Leukemia 2003, 17, 2230.

[19] Rotem, R.; Heyfets, A.; Fingrut, O.; Blickstein, D.; Shaklai, M.; Flescher, E. Cancer Res. 2005, 65, 1984.

[20] Gatenby, R.A.; Gillies, R.J. Nat. Rev. Cancer. 2004, 4, 891.

[21] Bonnet, S et al. Cancer Cell 2007, 11, 35.

[22] Buzzai, M.; Bauer, D.E.; Jones, R.G.; DeBerardinis, R.J.; Hatzivassiliou, G.; Elstrom, R.L.; Thompson, C. B.; Oncogene 2005, 24, 4165.

[23] Schimmer, A.D. Cancer Res. 2004, 64, 7183.

[24] Deveraux, Q.L.; Roy, N.; Stennicke, H.R.; Van Arsdale, T.; Zhou, Q.; Srinivasula, S.M.; Alnemri, E.S.; Salvesen, G.S.; Reed, J.C. EMBO J. 1998, $17,2215$.

[25] Chai, J.J.; Shiozaki, E.; Srinvasula, S.M.; Wu, Q.; Dataa, P.; Al-Nemri, E.S.; Shi, Y.G. Cell 2001, 104, 769. 
[26] Huang, Y.H.; Park, Y.C.; Rich, R.L.; Segal, D.; Myszka, D.G.; Wu, H. Cell 2001, 104, 781 .

[27] Riedl, S.J.; Renatus, M.; Schwarzenbacher, R.; Zhou, Q.; Sun, C.H.; Fesik, S.W.; Liddington, R.C.; Salvesen, G.S. Cell 2001, 104, 791.

[28] Du, C.Y.; Fang, M.; Li, Y.C.; Li, L.; Wang, X.D.; Cell 2000, 102, 33.

[29] Verhagen, A.M.; Ekert, P.G.; Pakusch, M.; Silke, J.; Connolly, L.M.; Reid, G.E.; Moritz, R.L.; Simpson, R.J.; Vaux, D.L. Cell 2000, 102, 43.

[30] LaCasse, E.C.; Baird, S.; Komeluk, R.G.; Mackenzie, A.E. Oncogene 1998, $17,3247$.

[31] Rajapakse, H.A. Curr. Top. Med. Chem. 2007, 7, 966.

[32] Hunter, A.M.; LaCasse, E.C.; Korneluk, R.G. Apoptosis 2007, 12, 1543.

[33] Simone, F. Exp. Rev. Anticancer Therap. 2007, 7, 1255.

[34] Nikolovska-Coleska, Z.; Xu, L.; Hu, Z.; Tomita, Y.; Li, P.; Roller, P.P.; Wang, R.; Fang, X.; Guo, R.; Zhang, M.; Lippman, M.E.; Yang, D.; Wang, S. J. Med. Chem. 2004, 47, 2430.

[35] Chen, J.Y.; Nikolovska-Coleska, Z.; Wang, G.P.; Qiu, S.; Wang, S.M. Bioorg. Med. Chem. Lett. 2006, 16, 5805.

[36] Oost, T.K.; Sun, C.; Armstrong, R.C.; Al-Assaad, A-S.; Betz, S.F.; Deckwerth, T.L.; Ding, H.; Elmore, S.W.; Meadows, R.P.; Olejniczak, E.T.; Oleksijew, A.; Oltersdorf, T.; Rosenberg, S.H.; Shoemaker, A.R.; Tomaselli, K.J.; Zou, H., Fesik, S.W. J. Med. Chem. 2004, 47, 4417.

[37] Reed, J. C. Oncogene 1998, 17, 3225.

[38] Zornig, M.; Hueber, A.O.; Baum, W.; Evan, G. Biochem. Biophys. Acta 2001, $1551, \mathrm{~F} 1$.

[39] Reed, J.C. Nat. Rev. Drug Discovery 2002, 1, 111. 
[40] Borner, C. Mol. Immunol. 2003, 39, 615.

[41] van Delft, M.F.; Huang, D.C.S. Cell Res. 2006, 16, 203.

[42] Wang, J.L.; Zhang, Z.J.; Choksi, S.; Shan, S.; Lu, Z.; Croce, C.M.; Alnemri, E.S.; Korngold, R.; Huang, Z. Cancer Res. 2000, 60, 1498.

[43] Huang, Z. Pharmacol. Ther. 2000, 68, 201.

[44] Sattler, M.; Liang, H.; Nettesheim, D.N.; Meadows, R.P., Harlan, J.E.; Eberstadt, M.; Yoon, H.S.; Shuker, S.B.; Chang, B.S.; Minn, A.J.; Thompson, C. B.W. Science 1997, 275, 983.

[45] www.ascenta.com

[46] Makin, G.; Dive, C. Trends Mol. Med. 2003, 9, 251.

[47] Wang, J.; Liu, D.; Zhang, Z.; Simei, S.; Han, X.; Srinivasula, S.M.; Croce, C.M.; Alnemri, E.S.; Huang, Z. Proc. Natl. Acad. Sci. U.S.A. 2000, 97, 7124.

[48] Lickliter, J.D.; Nood, N.J.; Johnson, L.; McHugh, G.; Tan, J.; Wood, F.; Cox, J.; Wickham, N.W. Leukemia 2003, 17, 2074.

[49] Dai, Y.; Rahmani, M.; Corey, S.J.; Dent, P.; Grant, S. J. Biol. Chem. 2004, $279,34227$.

[50] An, J.; Chen, Z.; Huang, Z. J. Biol. Chem. 2004, 279, 19133.

[51] Sinicrope, F.A.; Penington, R.C.; Tang, X.M. Clinical Cancer Res. 2004, 10, 8284.

[52] Pei, X.; Dai, Y.; Grant, S. Mol. Cancer Ther. 2004, 3, 1513.

[53] Doshi, J.M.; Tian, D.; Xing, C. J. Med.Chem. 2006, 49, 7731.

[54] Oliver, C.; Miranda, M.; Shangary, S.; Land, S.; Wang, S.; Johnson, D. Mol. Cancer Ther. 2005, 4, 23.

[55] Tuszynski, G.; Gossu, G. Cancer Res. 1984, 44, 768.

[56] Iso, W. Cancer Lett. 1984, 24, 257. 
[57] Coyle, T.; Levante, S.; Shetler, m.; Winfield, J. J. Neurooncol. 1994, 19, 25.

[58] Gilbert, N.; O’Reilly, J.; Chang, C.; Lin, Y.; Brueggemeier, R. Life Sci. 1995, 57,61 .

[59] Mohammad, R.; Wang, S.; Aboukameel, A.; Chen, B.; Wu, X.; Chen, J.; AlKatib, A. Mol. Cancer Ther. 2005, 4, 13.

[60] Wang, G.; Nikolovska-Coleska, Z.; Yang, C.; Wang, R.; Tang, G.; Guo, J.; Shangary, S,; Qiu, S.; Gao, W.; Yang, D.; Meagher, J.; Stuckey, J.; Krajewski, K.; Jiang, S.; Roller, P. P.; Abaan, H. O.; Tomita, Y.; Wang, S. J. Med. Chem. 2006, 49, 6139.

[61] Mohammad,R. M.; Goustin,A. S.; Aboukameel, A.; Chen, B.; Banerjee, S.; Wang, G.; Nikolovska-Coleska, Z.; Wang, S.; Al-Katib, A. Clin Cancer Res 2007, 13, 2226.

[62] Zeitlin, B. D.; Joo, E.; Dong, Z.; Warner, K.; Wang, G.; Nikolovska-Coleska, Z.; Wang, S.; Nor, J. E. Cancer Res. 2006, 66, 8698.

[63] Oltersdorf, T.; Elmore, S.W.; Shoemaker, A.R.; Armstrong, R.C.; Augeri, D.J.; Belli, B.A.; Bruncko, M.; Deckwerth, T.L.; Dinges, J.; Hajduk, P.J.; Joseph, M.K.; Kitada, S.; Korsmeyer, S.J.; Kunzer, A.R.; Letai, A.; Li, C.; Mitten, M.J.; Nettesheim, D.G.; Ng, S.; Nimmer, P.M.; O'Connor, J.M.; Oleksijew, A.; Petros, A.M.; Reed, J.C.; Shen, W.; Tahir, S.K.; Thompson, C.B.; Tomaselli, K.J.; Wang, B.; Wendt, M.D.; Zhang, H.; Fesik, S.W.; Rosenberg, S.H. Nature 2005, 435, 677.

[64] Real, P.; Cao, Y; Wang, R.; Nikolovska-Coleska, Z.;Sauz-Ortiz, J.; Wang, S; Fernandez-Luna, J. Cancer Res. 2004, 64, 7947.

[65] Liu, S.; Brown, C.W.; Berlin, K.D.; Dhar, A.; Guruswamy, S.; Brown, D.; Gardner, G.J.; Birrer, M.J.; Benbrook, D.M. J. Med. Chem. 2004, 47, 999. 
[66] Benbrook, D.M.; Kamelle, S.A.; Guruswamy, S.B.; Lightfoot, S.B.; Rutledge. T.L.; Gould, N.S.; Hannafon, B.N.; Dunn, S.T.; Berlin, K.D. Invest New Drugs 2005, 23, 417.

[67] Chun, K-H.; Benbrook, D.M.; Berlin, K.D.; Hong, W.K.; Lotan, R. Cancer Res. 2003, 63, 3826.

[68] Liu, T.; Hannafon, B.; Gill, L.; Kelly, W.; Benbrook, D.M. Mol. Cancer. Ther, 2007, 6, 1814.

[69] Zhang, Y.L.; Hua. Y.S.; Benbrook, D.M.; Covey, J.M.; Dai, G.W.; Chan, K.K. Cancer Chemother. Pharmacol. 2006, 58, 561.

[70] Walensky, L.D.; Kung, A.L.; Escher, I.; Malia, T.J.; Barbuto, S.; Wright, R.D.; Wagner, G.; Verdine, G.L.; Korsmeyer, S.J. Science 2004, 305, 1466.

[71] Walensky, L.D.; Pitter, K.; Morash, J.; Oh, K.J.; Barbuto, S.; Fisher, J.; Smith, E.; Verdine, G.L.; Korsmeyer, S.J. Mol. Cell. 2006, 24, 199.

[72] Zhang, H.Z.; Kasibhatla, S.; Kuemmerle, J.; Kemnitzer, W.; Oliis- Mason, K.; Qui, L.; Crogran-Grundy, C.; Tseng, B.; Drewe, J.; Cai, S.X. J. Med. Chem. $\mathbf{2 0 0 5}, 48,5215$.

[73] Jessen, K.; English, N.; Wang, J.; Qui, L.; Brand, R.; Maliartchouk, S.; Drewe, J.; Kuemmerle, J.; Zhang, H.Z.; Gehlsen, K.; Tseng, B.; Cai, S.X.; Kasibhatla, S. Mol. Cancer Ther. 2005, 4, 761.

[74] Diaz, E.; Pfeffer, S.R. Cell 1998, 93, 433.

[75] Than, G.N.; Turoczy, T.; Sumegi, B.; Than, N.G.; Bellyei, S.; Bohn, H.; Szekeres, G. Anticancer Res. 2001, 21, 639.

[76] Zhang, H.; Kasibhatla, S.; Wang, Y.; Herich, J.; Guastella, J.; Tseng, B.; Drewe, J.; Cai, S.X. Bioorg. Med. Chem. 2004, 12, 309.

[77] Yang, W.; Guastella, J.; Huang, J.; Wang, Y.; Drewe, J.; Xue, D.; Tran, M.; 
Woodward, R.; Kasibhatla, S.; Tseng, B.; Cai, S. Br. J. Pharmacol. 2003, 140, 402.

[78] Kasibhatla, S.; Jessen, K.; Maliartchouk, S.; Wang, J.; English, N.; Drewe, J.; Qui, L.; Archer, S.; Ponce, A.; Sirisoma, N.; Jiang, S.; Zhang, H.; Gehlsen, K.; Cai, S.; Green, D.; Tseng, B. Proc. Natl. Acad. Sci. USA 2005, 102, 12095.

[79] Ryschich, E.; Huszty, G.; Knaebel, H.; Hartel, M.; Buchler, M.; Schmidt, J. Eur. J. Cancer 2004, 40, 1418. 